\title{
Biomarkers in Pediatric Sepsis
}

\author{
Kristen Smith and Michael T. Bigham*
}

Division of Critical Care Medicine, Akron Children's Hospital, Akron, OH, USA

We should spend more time learning how to achieve an accurate diagnosis and less time searching for a magic bullet...Roger Bone (1996) [1]

\section{INTRODUCTION}

Sepsis is a leading killer of both adult and pediatric patients, and delays in recognition and treatment significantly increase the risk of morbidity and mortality [2, $3]$. The concept of early detection serves as the foundation for the search for clinically viable indicators of severe sepsis and septic shock - hence the interest in sepsis biomarkers. A biomarker is defined as the biological parameters associated with the presence and severity of specific disease states. Biomarkers are detectable and measurable by a variety of methods including physical examination, laboratory assays, and medical imaging. Specifically, a biomarker is a characteristic that is objectively measured and evaluated in a normal biologic process, in a pathologic process, or as a pharmacologic response to a therapeutic intervention [4]. For sepsis, a "good" biomarker may permit earlier diagnosis, earlier treatment, and thus reduced morbidity and mortality.

The concept of an "ideal" sepsis biomarker is worthy of exploration. First, an ideal sepsis biomarker would accurately detect the presence of infection in a patient. That is, an ideal sepsis biomarker would detect all cases of sepsis and would have no false positive tests. Next, a sepsis biomarker must be easily tested. If a sepsis biomarker were $100 \%$ sensitive and $100 \%$ specific in all patient populations at the exact moment that even a single infectious organism comes in contact with a patient - it would seem appealing. However, if the biomarkers were only available via a laborious or invasive technique (i.e. a cardiac biopsy) - that appeal would lessen, due to the difficulty in obtaining the sample. Most of the acceptable biomarkers are obtained via blood sample or swabs, and the biomarkers described in this sepsis review are serum markers. An ideal sepsis biomarker should provide a rapid "turn-around" time. If a biomarker were sensitive, specific, and obtained easily - but provided testing results after a long delay, the biomarker might be ineffective. Severe sepsis and septic shock often progress rapidly and delays in diagnosis and treatment are critical.

There are conceptually only 2 physiologic targets for sepsis biomarkers - biomarkers related to the infectious agent or related to the body's response to the infectious agent. Infectious components that might serve as biomarkers

\footnotetext{
*Address correspondence to this author at the Division of Critical Care, Akron Children's Hospital, Akron, OH, USA Medicine;

Tel / Fax: (330) 543-8639; E-mail: mbigham@chmca.org
}

are bacterial cellular components, bacterial DNA, or even viral RNA/DNA. Alternatively, the body's response to infection might allow for the targeting of cytokines, coagulation markers, inflammatory markers, acute phase reactants, markers of dysoxia, and even soluble receptors. The majority of sepsis biomarkers, to date, focus on the body's response to infection. The limitations of this approach are highlighted in the neonatal and pediatric intensive care units and include physiological variation among the response to sepsis based on age, genetics, infectious agents, and comorbid conditions. Specifically, the relative immunologic immaturity of a neonate provides a uniquely challenging physiologic milieu when targeting sepsis biomarker design [5]. More unique is the immunosuppressed oncologic or transplant patient, where "normal" physiologic response to sepsis might be highly modified by specific immunosuppressive agents [6]. Expectantly, this approach limits the transportability for any single biomarker across patient populations.

Using a single or set of biomarkers for sepsis has clear benefits related to early diagnosis and intervention. There are, however, risks of using biomarkers to define a disease, in this case sepsis. One risk lies in false positive test results that is a biomarker test result indicates that the patient has sepsis when they don't have sepsis [7]. This could lead to aggressive treatment, prolonged hospitalization, and ultimately unnecessary therapy. Additionally, and possibly more risky, is the danger of narrowing the differential diagnosis too early. So not only might unnecessary therapy be initiated but the necessary diagnostic testing or therapy for a patient's actual disease could be delayed.

With that foundation laid, the challenge to define the current evidence around biomarkers for sepsis is a daunting one. A simple PubMed search of "sepsis AND biomarker" yields over 3,300 matches, an improvement from the 26,000 plus hits when searching "infection AND biomarker." A summary of the key literature is included for the purpose of this review, though expectantly as technology improves the sepsis biomarker science is likely to evolve rapidly. The format for this biomarker discussion includes a review of the major biomarkers and their efficacy as sepsis biomarkers, the physiologic basis for each target, descriptions of the laboratory test(s), and specific applications in unique populations.

\section{C-REACTIVE PROTEIN (CRP)}

C-reactive protein (CRP) is widely used as a marker of acute inflammation and one of the more studied sepsis biomarkers. It is produced by the liver in response to 
interleukin (IL)-6 generated during the inflammatory response to cellular injury. CRP is thought to assist in complement binding to foreign and damaged cells [8-12]. CRP is found to increase later in the course of sepsis than other biomarkers such as IL-6 and IL-1 [9]. Sensitivity of $\mathrm{CRP}$ in diagnosing sepsis ranges from $44 \%$ to $100 \%$. Specificity ranges from $58 \%$ to $98 \%$, depending upon the cut-off value used (Table 1). CRP is a marker of inflammation, and not of infection. As such, it may be elevated in many other conditions such as viral infection, malignancy, trauma, post-operative, burn injury, tissue necrosis, immunologically-mediated inflammatory diseases, crystal-induced inflammatory diseases, and even obesity [13, 14]. CRP is $87-97 \%$ specific and $15-29 \%$ sensitive in diagnosing neonatal sepsis and particularly less useful in preterm infants [15]. Although a positive CRP will only increase probability of infection by $11 \%$, a negative CRP decreases probability of infection 33\% [16]. All neonatal patients, as well as pediatric patients with liver failure or undergoing steroid treatment, have decreased CRP levels in response to infection due to decreased cytokine activation $[14,15]$.

In a trial with procalcitonin (PCT) and serum amyloid (SAA), CRP was found to have the same diagnostic capability for neonatal bacterial sepsis, but not in the early phase. In children, however, PCT is superior [8]. In patients with known sepsis, CRP was compared with sepsis-related organ failure assessment (SOFA) scores and found to be higher at lower SOFA levels, indicating that CRP is not a direct measure of clinical progression, therefore not helpful in providing information about further organ dysfunction because it is already to a maximum level at the time organ dysfunction arises [17]. CRP, when used in combination with IL-6, is a reliable marker of early infection and disease progression. IL-6 rises fast, but has a short half-life, so CRP is used to monitor disease after the 24-hour mark [11]. CRP rises over 2-3 days, peaking at 36-50 hours after the insult [13].

CRP is a serum measurement. A volume of 2-3 milliliters of blood is required [18]. The assay is run by either nephelometry or immunoturbidity [11]. This involves combining CRP-containing serum with its specific CRP antibody to form antigen-antibody complexes that are insoluble. A beam of light from an infrared light emitting diode or detector is passed through a test tube containing CRP-antibody complexes. The amount of light scattered is measured from different angles using a nephelometric device, handheld turbidimeter, or automated analyzer. The amount of CRP is proportional to the amount of light scattered [19]. The assay can cost anywhere from two to five dollars and the turn-around time ranges from 2-6 hours [13].

\section{ERYTHROCYTE SEDIMENTATION RATE (ESR)}

Another commonly discussed sepsis biomarker is the erythrocyte sedimentation rate (ESR) which is a non-specific marker of tissue injury [20]. ESR has been shown to be more useful than leukocyte count in identifying inflammatory conditions. In fact, ESR is even useful in differentiating mild versus severe states of inflammation. Sensitivity and specificity are consistently high ESR in detection of inflammatory diseases and malignancy [13]. ESR is less useful, however, in categorizing the etiology behind the highly inflamed patients (i.e. differentiating malignancy versus infection) [13]. Hence, ESR is a nonspecific marker of inflammation with very limited specificity in diagnosing sepsis.

In burn patients who often sustain high levels of inflammation, ESR was found to be elevated but not different between infected and non-infected burn patients [13]. The use of ESR as an indicator of sepsis in neonates has proven useless as sedimentation is low in the newborn state due to high hematocrit [20]. Low baseline ESR exists in cases of decreased fibrinogen, sickle cell disease, polycythemia, or congestive heart failure [21].

The ESR test actually measures the rate at which red blood cells precipitate over one hour and is reported in millimeters per hour $(\mathrm{mm} / \mathrm{h})$. ESR measurement is available in most hospital laboratories and requires 2-4 milliliters of blood. The test is inexpensive, costing around two dollars [18]. Because of the intrinsic time required to allow erythrocyte precipitation, the test takes about 2 hour to result.

\section{PROCALCITONIN}

Procalcitonin (PCT) is gaining attention as a sepsis biomarker. PCT is a precursor protein of calcitonin which is produced by the thyroid $\mathrm{C}$ cells during normal physiologic conditions. In cases of sepsis, however, PCT has an extrathyroidal origin and is produced in response to endotoxin (gram negative sepsis) and/or cytokines involved in the sepsis cascade $[14,22]$. PCT has been found to be an indicator of bacterial and fungal infection in cases of pneumonia [23], acute respiratory distress syndrome [24], systemic inflammatory response syndrome [16], sepsis [13], shock [25], post-operative and trauma patients [22], and oncologic conditions [14]. Not only has PCT been found to be a marker of infection in general, but has also been shown to increase as disease severity worsens, and although the mode of action during times of sepsis is unclear, PCT has been implicated in mediating the inflammatory process [8].

Multiple studies have shown that PCT levels are markedly higher in patients with sepsis than in healthy controls $[8,26]$, and in some studies has been found to be superior to other biomarkers, especially CRP $[15,16,18$, 22]. In a head-to-head comparison with CRP, PCT rises faster (4 hours compared to 6 hours in CRP), peaks faster ( 8 hours compared to $36-50$ hours), normalizes more quickly (48 hours after appropriate therapy compared to 72-96 hours) and is more sensitive and specific to sepsis $(92.6 \%$ and $97.5 \%$ respectively) [26].

PCT has been studied in multiple patient populations. The only population of patients where PCT does not seem to be an accurate measure of infection and disease severity is the neonate. PCT undergoes a physiologic rise in the noninfected neonate, especially in the first 72 hours of life [27], so it is not a reliable marker for infection in such patients. Beyond the neonatal period, PCT seems to be equally efficacious in use for pediatric and adult inflammatory processes [22].

Since PCT has shown efficacy in indicating presence of infection, it has begun to be implicated as a potential 
biomarker of interest in specific patient populations as well. In the hematology/oncology wards, it has been found to be of limited diagnostic value in patients undergoing T-celldirected immunosuppressive therapy, granulocyte support, or who are in the acute stages of graft-versus-host disease [14]. In patients who required surgery or were victims of trauma, PCT was found to be a useful biomarker in diagnosing sepsis, but was of no additional value in this population when compared to non-surgical critically ill patients [22]. It was found, however that the cutoff value for PCT in diagnosing sepsis should be higher in patients who have had a surgical aspect to their care because of its role in inflammation as well as infection [25]. PCT has also been implicated as being useful in the post-transplant patient [28]. Though PCT levels are higher in all surgical patients, heart transplant recipients with levels above $80 \mathrm{ng} / \mathrm{mL}$ were significant in predicting complications and increased mortality [17].

The logistics of using PCT as a potential marker for sepsis include turnaround time and accuracy. It has already been said that specificity and sensitivity are $>90 \%$. The laboratory test requires $2 \mathrm{~mL}$ of clotted blood and results can be reported in 2 hours [26]. The assay requires the sample to be centrifuged and the serum to be frozen at $-70^{\circ} \mathrm{C}[8,27]$. The assay can be run from a variety of commercially available methods, but the most commonly used assay is the Brahms automated immunofluorescent assay.

\section{INTERLEUKIN (IL)-6}

The interleukins have been logical targets of sepsis biomarker investigations related to their role in inflammation and sepsis. Interleukin-6 (IL-6) is a pro-inflammatory cytokine that is produced in response to infection and other conditions of inflammation [8, 11]. IL-6 is an integral part of the cytokine activation cascade [10]. IL-6 is found to inhibit tumor necrosis factor-alpha and interleukin-1 but activate interleukin-1 receptor antagonist and interleukin-10 [12].

In gram-negative sepsis in neonates, using an IL-6 cutoff value of $18.2 \mathrm{pg} / \mathrm{mL}$, sensitivity for diagnosing sepsis was $87 \%$, specificity was $50 \%$. When compared to C-reactive protein (CRP), IL-6 was found to be less useful in early diagnosis of sepsis as a single biomarker [8]. In another study looking at children with sepsis and septic shock, IL-6 was compared to procalcitonin (PCT) and IL-6 levels were markedly higher at zero and twelve hours in the septic shock group and septic group [10]. Magudumana et al. also looked at sepsis in neonates and found that a combination of IL-6 and CRP gave the best prediction of infection and that IL-6 alone at the first sign of early infection can decrease the amount of unnecessary antibiotics in the neonatal intensive care unit [11].

IL-6 is a serum measurement requiring $1 \mathrm{ml}$ of blood. The serum test can either be a sandwich enzyme-linked immunosorbent assay (ELISA) or a solid phase chemiluminescent assay $[8,9]$. Incubation takes approximately 30 minutes and results are available in 1-3 hours. Cost ranges from five to twenty dollars for ELISA and chemiluminescent assays, respectively $[8,9]$.

Drawbacks of use of IL-6 as a biomarker in sepsis include cost and sensitivity. The cost of the assay seems to offset the benefit neonates would receive in terms of shortened hospital stay and increased availability of highrisk intensive care beds $[8,9]$. IL-6 has a physiologic rise in the neonate peaking on day one of life. IL-6 has reported sensitivity of $76-100 \%$ and specificity of $70-96 \%$ indicating a wide range in clinical applicability. Equal numbers of infected and non-infected patients had elevation the day prior to clinical manifestation of sepsis [12].

\section{INTERLEUKIN-1 RECEPTOR ANTAGONIST (IL-1ra)}

Interleukin-1 receptor antagonist (IL-1ra) is the receptor antagonist of IL-1 $\beta$. Levels reach peak at 2-4 hours after experimental endotoxin administration. IL-1 ra remains elevated for more than 24 hours after endotoxin [13]. One drawback of using IL-1ra as a biomarker in diagnosing sepsis is that it can be found in the serum at different levels in neonates of different gestational ages and those with noninfectious neonatal disease. This has proven challenging in setting standard cutoff levels, thus normal values are not readily available. IL-1ra is a serum measurement and the assay is an ELISA [13].

In neonatal sepsis, IL-6 and IL-1ra were increased 2 days prior to development of signs or symptoms of clinical disease in very low birth weight infants, and IL-1ra increased in all patients with clinically diagnosed sepsis [13]. IL-1 ra has a longer half-life than IL-6, potentially making a better biomarker in diagnosing sepsis.

\section{INTERLEUKIN (IL)-8}

Interleukin-8 (IL-8) is an inflammatory cytokine that is released from monocytes, endothelial cells, and neutrophils in response to IL- 1 and TNF- $\alpha$. IL-8 responds by activating $\mathrm{T}$ cells, neutrophils and basophils [29]. Increases in circulating IL-8 are seen early in the infectious course. IL-8 is measured in the serum by a variety of enzyme immunoassays that are commercially available. IL-8 peaks at 2.5-3 hours [30]. The cost of the test is approximately $\$ 15$ and results are available within 5 hours.

In a study of oncology patients with febrile neutropenia, IL-8 levels were elevated earlier and higher in patients with gram-negative sepsis from E. coli or K. pneumonia. Levels were likewise elevated in gram-positive sepsis, but less-so than with gram-negative infection [31]. In a recent study observing at biomarkers in meningococcemia, IL-8 levels were significantly higher in non-survivors, indicating that IL-8 elevation would correlate with more severe disease [32].

There has been much research in finding an appropriate biomarker profile to accurately predict sepsis. While IL-8 alone does not seem to be adequate in predicting sepsis, when combined with other biomarkers, promising results have been presented. A recent study looked at IL-1Ra, TNF, IL-6, and IL-8 as biomarkers of sepsis and found that a profile consisting of high IL-1Ra: TNF, IL-1Ra: IL-6 and IL1Ra: IL-8 were associated with more severe disease and septic shock [33]. Another study found a sensitivity of $96 \%$ in determining sepsis in neonates when IL-8 was combined with CRP [34].

\section{TUMOR NECROSIS FACTOR (TNF)- $\alpha$}

Another popular sepsis biomarker target is tumor necrosis factor-alpha (TNF- $\alpha$ ), a pro-inflammatory cytokine 
that is known to mediate inflammatory conditions including sepsis [35]. It is produced by dendritic cells, activated T cells and monocytes, macrophages, Langerhans cells, keratinocytes, fibroblasts, and astrocytes in response to cellular insult $[35,36]$. Acting as one of the primary agents in initiating the cellular response to sepsis, TNF- $\alpha$ regulates the body's immune response by influencing production of a variety of cells including prothymocytes and thymocytes. In addition, TNF- $\alpha$ activates macrophages and NK cells in the cytotoxic cascade [27, 35].

One of the benefits of TNF- $\alpha$ is that it rises early. The cytokine peaks at one hour after exposure to infectious element but is no longer detectable in the serum at 3 hours [37]. During this time, however, TNF- $\alpha$ is binding to soluble cellular receptors that are shed. This provides another potential diagnostic marker to track once TNF- $\alpha$ itself is no longer detectable [38].

It is known that TNF- $\alpha$ rises during infection in the adult population [39]. The utility of TNF- $\alpha$ as a biomarker in sepsis in children, however, is not well studied. Ucar looked at TNF- $\alpha$ in comparison to serum amyloid A and IL-1, among others, and found that TNF- $\alpha$ is not as useful in diagnostic capabilities in neonatal sepsis [27]. In children with meningococcemia, it has been shown that TNF- $\alpha$, together with IL-6 induce the acute phase response spearheaded by CRP, but laboratory correlation between the three biomarkers is less straightforward in providing a tracking tool for improvement [38]. Statistical analysis is quite variable (See Table 2). The sensitivity of TNF- $\alpha$ in culture-confirmed sepsis to be $83.3 \%$ on day zero [27]. Using a cut-off value of $12 \mathrm{pg} / \mathrm{mL}$, sensitivity can reach as high as $87.9 \%$, but lower cut-off values are often used to increase specificity. Using the same cut-off, but combining TNF- $\alpha$ with IL-6 levels, one can increase sensitivity for detecting neonatal sepsis to $98.5 \%$ [37]. Santana Reyes found that using TNF- $\alpha$ alone as a single diagnostic marker in early diagnosis of neonatal sepsis is not advisable based on sub-optimal specificity [40]. The major drawback in using TNF- $\alpha$ as a sole biomarker in tracking sepsis is its short half-life in the blood [39]. The cost is comparable to other assays. The assay is a sandwich ELISA requiring $2 \mathrm{~mL}$ of blood to be kept at $-72^{\circ} \mathrm{C}$ until aliquot can be analyzed [37].

\section{TRIGGERING RECEPTOR EXPRESSED ON MYE- LOID CELLS (TREM)-1}

Triggering receptor expressed on myeloid cells-1 (TREM-1) is a member of an immunoglobulin superfamily that is upregulated in response to bacteria or fungi. When bound, TREM-1 stimulates the release of cytokines such as TNF- $\alpha$ and IL-1 $\beta$ [41]. A benefit of TREM- 1 is that it is not elevated in non-infectious inflammatory disorders [31]. One drawback of TREM-1 is that it is not easily identified in body fluids. A soluble form of TREM-1 (sTREM) is, however, detectable and therefore serves as a more beneficial option for a biomarker predictive of sepsis [42]. sTREM is also higher in patients with septic shock than those with sepsis or severe sepsis [43].

STREM seems to be an accurate laboratory marker of sepsis. Sensitivity ranges from $96-98 \%$ and specificity is 89 $90 \%$ [41]. A recent study showed that sTREM levels seemed to be protective against death likely indicating that early inflammatory response to infection leads to better clinical outcomes. The same study also showed a progressive decline in STREM levels as the clinical picture improved [41]. A positive correlation has been found between sTREM and SOFA scores, as well [44]. In a comparison study between procalcitonin, CRP and STREM it was found that sTREM levels were significantly lower in non-survivors. Elevated sTREM levels on admission to the ICU seem to serve as a protective factor in the same population, and STREM levels decline as clinical improvement is seen [45]. Other adult studies have demonstrated conflicting results, showing no difference in sTREM levels in adults with SIRS, sepsis, or severe sepsis when compared with healthy controls [46].

sTREM appears to peak at around 2 hours after infectious exposure [43], and sustained elevation of sTREM appears to predict a poor outcome [42]. The cost of sTREM assay is $\$ 30$ and results can take up to 5 hours. STREM levels are measured by ELISA [46].

\section{HIGH MOBILITY GROUP BOX (HMGB) 1}

High mobility group box 1 (HMGB1) is a chromatin protein that was first described in the 1970's through copurification with histone from thymic nuclei. Localized to both the nucleus and the cytoplasm, HMBG1 appears to contribute to nucleosomal structure and stability, though it appears to be shuttled between cytoplasm and nucleus [47].

Table 1. CRP Values and their Correlating Prevalence, Sensitivity, and Specificity for Sepsis

\begin{tabular}{|c|c|c|c|c|}
\hline & CRP Cut-off & Prevalence & $\begin{array}{c}\text { Sensitivity } \\
(95 \% \mathrm{CI})\end{array}$ & $\begin{array}{r}\text { Specificity } \\
\text { (95\% CI) }\end{array}$ \\
\hline Pulliam et al., 2001 [59] & $7 \mathrm{mg} / \mathrm{dL}$ & $18 \%$ & $79(57-100)$ & $90(83-98)$ \\
\hline Lacour et al., 2001 [60] & $40 \mathrm{mg} / \mathrm{L}$ & $23 \%$ & $89(78-100)$ & $75(66-84)$ \\
\hline Berger et al., 1996 [62] & $20 \mathrm{mg} / \mathrm{L}$ & $25 \%$ & $83(70-97)$ & $67(58-76)$ \\
\hline Andreola et al., 2007 [26] & $>40 \mathrm{mg} / \mathrm{L}$ & $67 \%$ & $71(61-80)$ & $81(76-85)$ \\
\hline
\end{tabular}


Table 2. Statistical Comparison of Sensitivity and Specificity of TNF- $\alpha$ as a Sole Diagnostic Marker of Sepsis in Children

\begin{tabular}{|c|c|c|c|}
\hline & Sensitivity (\%) & Specificity (\%) & Cut-off Value (pg/mL) \\
\hline \hline Ucar et al. $[$ [27] & 83.3 & 80.6 & 1 \\
\hline Santana Reyes et al. $[$ [40] & 92 & 54 & 1 \\
\hline Silveira et al. [37] & 87.9 & $43 \%$ & 12 \\
\hline
\end{tabular}

Table 3. Summary of Advantages and Disadvantages of Each Candidate Biomarker for Neonatal/Pediatric Sepsis. $($ CRP $=$ CReactive Protein, ESR = Erythrocyte Sedimentation Rate, IL = Interleukin, TNF- $\alpha=$ Tumor Necrosis Factor - Alpha, TREM-1 = Triggering Receptor Expressed on Myeloid Cells, and HMGB1 = High Mobility Group Box 1)

\begin{tabular}{|c|c|c|}
\hline CRP & $\begin{array}{ll}\text { - } & \text { Relatively insensitive and nonspecific } \\
\text { - } & \text { Inexpensive }\end{array}$ & $\begin{array}{l}\text { - } \quad \text { Elevated in all states of inflammation } \\
\text { - No correlation with disease severity (SOFA } \\
\text { score) }\end{array}$ \\
\hline ESR & $\begin{array}{l}\text { - More sensitive than leukocyte count for infection } \\
\text { - Inexpensive }\end{array}$ & $\begin{array}{l}\text { - } \quad \text { Elevated in all states of inflammation } \\
\text { - } \quad \text { Not useful in neonates }\end{array}$ \\
\hline Procalcitonin & $\begin{array}{l}\text { - } \quad \text { More sensitive/specific than CRP for sepsis } \\
\text { - } \quad \text { Correlates to disease severity with sepsis }\end{array}$ & - $\quad$ Peaks very early, wanes early \\
\hline IL-6 & - Proinflammatory cytokine integral in cytokine cascade & - Lacks sensitivity and specificity \\
\hline IL-1 ra & - Elevated in neonates who went on to develop sepsis & $\begin{array}{l}\text { - Neonatal levels influenced by gestational age } \\
\text { and secondary causes of inflammation }\end{array}$ \\
\hline TNF- $\alpha$ & $\begin{array}{ll}\text { - } & \text { Peaks early } \\
\text { - } & \text { Primary agent triggering cellular response to sepsis }\end{array}$ & - Very short serum half-life \\
\hline TREM-1 & $\begin{array}{l}\text { - } \quad \text { Specific to infectious inflammation } \\
\text { - } \quad \text { Soluble form is detectable in body fluids }\end{array}$ & - $\quad$ Limited pediatric data \\
\hline HMGB1 & - $\quad$ Correlation with disease severity (SOFA score) & - $\quad$ Limited human and pediatric studies \\
\hline
\end{tabular}

Cytokine (TNF- $\alpha$, IFN- $\gamma$ ) stimulated macrophages release HMGB1 and endotoxin induces "late" release of HMGB1. Animal models of endotoxemia resulted in serum detection of HMGB1 at $8 \mathrm{hrs}$ and direct endotoxin infusion resulted in plateau levels from 16-32 hours [48-50]. Aside from inflammatory release of HMGB1, necrotic and damaged cells are also sources of serum HMGB1. Late treatments with ethyl pyruvate decreases serum accumulation of HMGB1 in septic mice and the HMGB1 antagonist, "A box," rescues mice from severe sepsis [51, 52]. AntiHMGB1 antibodies have shown to reduce endotoxin-induced acute lung injury and increase survival when administered late in animal models [53].

In humans, HMGB-1 was significantly elevated in patients with DIC when compared to patients with trauma, infectious diseases, and malignancies. In the DIC cohort, the non-survivors had significantly higher serum HMGB1 levels and correlated with both DIC scores and sepsis-related organ failure assessment (SOFA) score [54]. A case report describes the use of direct hemoperfusion with a polymyxin
B immobilized fiber column in a septic patient and documented a reduction in endotoxin, interleukin 6 (IL-6), and HMGB1 [55]. A cohort of patients exposed to similar direct hemoperfusion showed improved mortality and an associated reduction in HMGB1 levels following polymyxin B-immobilized fiber column [56]. In humans with surgical sepsis, HMGB1 were elevated when compared to healthy volunteers, and HMGB1 levels were significantly higher in septic nonsurvivors versus survivors [49].

\section{CONCLUSION}

In summary the data for sepsis biomarkers in pediatric sepsis can be confusing (Table 3). Many individual studies have shown promise, and some studies combining multiple biomarkers show promise as well. However, the problems remain with transportability of biomarker tests among different pediatric and neonatal populations. Also, there is still caution amongst front-line care providers with implementing biomarker assays to universally drive care largely due to false-positivity rates. The near future use of 
biomarkers of pediatric severe sepsis and septic shock may be applied for stratification of risk among critically ill children. Wong, et. al. described the use of IL-8 as a risk stratification tool for prospective clinical trials allowing mortality to be used as real endpoints in the "high risk" population suffering from severe sepsis/septic shock [57]. To date, there is no single or combined biomarker assay that is employed broadly amongst pediatric hospitals.

\section{REFERENCES}

[1] Bone RC. Newton, sepsis, SIRS, and CARS. Crit Care Med 1996; 24: $1125-8$.

[2] Kutko MC, Calarco MP, Flaherty MB, et al. Mortality rates in pediatric septic shock with and without multiple organ system failure. Pediatr Crit Care Med 2003; 4(3): 333-7.

[3] Odetola FO, Gebremariam A, Freed GL. Patient and hospital correlates of clinical outcomes and resource utilization in severe pediatric sepsis. Pediatrics 2007; 119(3): 487-94.

[4] Biomarkers Definitions Working Group. Biomarkers and surrogate endpoints: preferred definitions and conceptual framework. Clin Pharmacol Ther 2001; 69(3): 89-95.

[5] Schelonka RL, Infante AJ. Neonatal immunology. Semin Perinatol 1998; 22(1): 2-14

[6] Allen UD. Factors influencing predisposition to sepsis in children with cancers and acquired immunodeficiencies unrelated to human immunodeficiency virus infection. Pediatr Crit Care Med 2005; 6(Suppl 3): S80-6.

[7] Roongsritong C, Warraich I, Bradley C. Common causes of troponin elevations in the absence of acute myocardial infarction: incidence and clinical significance. Chest 2004; 125(5): 1877-84.

[8] Enguix A, Rey C, Concha A, Medina A, Coto D, Dieguez MA. Comparison of procalcitonin with C-reactive protein and serum amyloid for the early diagnosis of bacterial sepsis in critically ill neonates and children. Intensive Care Med 2001; 27(1): 211-5.

[9] Kuster H, Weiss M, Willeitner AE, et al. Interleukin-1 receptor antagonist and interleukin-6 for early diagnosis of neonatal sepsis 2 days before clinical manifestation. Lancet 1998; 352(9136): 12717.

[10] Luzzani A, Polati E, Dorizzi R, Rungatscher A, Pavan R, Merlini A. Comparison of procalcitonin and C-reactive protein as markers of sepsis. Crit Care Med 2003; 31(6): 1737-41.

[11] Magudumana MO, Ballot DE, Cooper PA, et al. Serial interleukin 6 measurements in the early diagnosis of neonatal sepsis. J Trop Pediatr 2000; 46(5): 267-71.

[12] Sanders S, Barnett A, Correa-Velez I, Coulthard M, Doust J. Systematic review of the diagnostic accuracy of C-reactive protein to detect bacterial infection in nonhospitalized infants and children with fever. J Pediatr 2008; 153(4): 570-4.

[13] Barati M, Alinejad F, Bahar MA, et al. Comparison of WBC, ESR, CRP and PCT serum levels in septic and non-septic burn cases. Burns 2008; 34(6): 770-4.

[14] Dornbusch HJ, Strenger V, Sovinz P, et al. Non-infectious causes of elevated procalcitonin and C-reactive protein serum levels in pediatric patients with hematologic and oncologic disorders. Support Care Cancer 2008; 16(9): 1035-40.

[15] Sherwin C, Broadbent R, Young S, et al. Utility of interleukin-12 and interleukin-10 in comparison with other cytokines and acutephase reactants in the diagnosis of neonatal sepsis. Am J Perinatol 2008; 25(10): 629-36.

[16] Simon L, Saint-Louis P, Amre DK, Lacroix J, Gauvin F. Procalcitonin and C-reactive protein as markers of bacterial infection in critically ill children at onset of systemic inflammatory response syndrome. Pediatr Crit Care Med 2008; 9(4): 407-13.

[17] Meisner M, Rauschmayer C, Schmidt J, et al. Early increase of procalcitonin after cardiovascular surgery in patients with postoperative complications. Intensive Care Med 2002; 28(8): 1094-102.

[18] Sakha K, Husseini MB, Seyyedsadri N. The role of the procalcitonin in diagnosis of neonatal sepsis and correlation between procalcitonin and C-reactive protein in these patients. Pak J Biol Sci 2008; 11(14): 1785-90.

[19] Hengst JM. The role of C-reactive protein in the evaluation and management of infants with suspected sepsis. Adv Neonatal Care 2003; 3(1):3-13.
[20] Parida SN, Verma IC, Singh MB, Thomas S. Evaluation of micro erythrocyte sedimentation rate in the diagnosis of neonatal sepsis. Indian J Pediatr 1980; 47(388): 381-4.

[21] Greer JP, Foerrster J, Rodgers G, et al. Wintrobe's Clinical Hematology. $12^{\text {th }}$ ed. Philadelphia: Lippincott, Williams, and Wilkins 2008.

[22] Meisner M, Adina H, Schmidt J. Correlation of procalcitonin and C-reactive protein to inflammation, complications, and outcome during the intensive care unit course of multiple-trauma patients. Crit Care 2006; 10(1): R1.

[23] Dubos F, Korczowski B, Aygun DA, et al. Serum procalcitonin level and other biological markers to distinguish between bacterial and aseptic meningitis in children: a European multicenter case cohort study. Arch Pediatr Adolesc Med 2008; 162(12): 1157-63.

[24] Tseng JS, Chan MC, Hsu JY, Kuo BI, Wu CL. Procalcitonin is a valuable prognostic marker in ARDS caused by communityacquired pneumonia. Respirology 2008; 13(4): 505-9.

[25] Fioretto JR, Martin JG, Kurokawa CS, et al. Interleukin-6 and procalcitonin in children with sepsis and septic shock. Cytokine 2008; 43(2): 160-4.

[26] Andreola B, Bressan S, Callegaro S, Liverani A, Plebani M, Da Dalt L. Procalcitonin and C-reactive protein as diagnostic markers of severe bacterial infections in febrile infants and children in the emergency department. Pediatr Infect Dis J 2007; 26(8): 672-7.

[27] Ucar B, Yildiz B, Aksit MA, et al. Serum amyloid A, procalcitonin, tumor necrosis factor-alpha, and interleukin-1beta levels in neonatal late-onset sepsis. Mediators Inflamm 2008; 2008: 737141.

[28] Hammer S, Meisner F, Dirschedl P, et al. Procalcitonin for differential diagnosis of graft rejection and infection in patients with heart and/or lung grafts. Intensive Care Med 2000; 26 (Suppl 2): S182-6.

[29] Diepold M, Noellke P, Duffner U, Kontny U, Berner R. Performance of Interleukin-6 and Interleukin-8 serum levels in pediatric oncology patients with neutropenia and fever for the assessment of low-risk. BMC Infect Dis 2008; 8: 28.

[30] Blackwell TS, Christman JW. Sepsis and cytokines: current status. Br J Anaesth 1996; 77(1): 110-7.

[31] Lehrnbecher T, Venzon D, de Haas M, Chanock SJ, Kuhl J. Assessment of measuring circulating levels of interleukin-6, interleukin-8, C-reactive protein, soluble Fc gamma receptor type III, and mannose-binding protein in febrile children with cancer and neutropenia. Clin Infect Dis 1999; 29(2): 414-9.

[32] Vermont CL, Hazelzet JA, de Kleijn ED, van den Dobbelsteen GP, de Groot R. CC and CXC chemokine levels in children with meningococcal sepsis accurately predict mortality and disease severity. Crit Care 2006; 10(1): R33.

[33] Carrol ED, Thomson AP, Jones AP, Jeffers G, Hart CA. A predominantly anti-inflammatory cytokine profile is associated with disease severity in meningococcal sepsis. Intensive Care Med 2005; 31(10): 1415-9.

[34] Franz AR, Bauer K, Schalk A, et al. Measurement of interleukin 8 in combination with $\mathrm{C}$-reactive protein reduced unnecessary antibiotic therapy in newborn infants: a multicenter, randomized, controlled trial. Pediatrics 2004; 114(1): 1-8.

[35] Zidi I, Mestiri S, Bartegi A, Amor NB. TNF-alpha and its inhibitors in cancer. Med Oncol 2010; 27(2): 185-98.

[36] Njau F, Wittkop U, Rohde M, Haller H, Klos A, Wagner AD. In vitro neutralization of tumor necrosis factor-alpha during Chlamydia pneumoniae infection impairs dendritic cells maturation/function and increases chlamydial progeny. FEMS Immunol Med Microbiol 2009; 55(2): 215-25.

[37] Silveira RC, Procianoy RS. Evaluation of interleukin-6, tumour necrosis factor-alpha and interleukin-1beta for early diagnosis of neonatal sepsis. Acta Paediatr 1999; 88(6): 647-50.

[38] Dollner H, Vatten L, Austgulen R. Early diagnostic markers for neonatal sepsis: comparing C-reactive protein, interleukin-6, soluble tumour necrosis factor receptors and soluble adhesion molecules. J Clin Epidemiol 2001; 54(12): 1251-7.

[39] Doellner H, Arntzen KJ, Haereid PE, Aag S, Brubakk AM, Austgulen R. Increased serum concentrations of soluble tumor necrosis factor receptors p 55 and p 75 in early onset neonatal sepsis. Early Hum Dev 1998; 52(3): 251-61.

[40] Santana RC, Garcia-Munoz F, Reyes D, Gonzalez G, Dominguez C, Domenech E. Role of cytokines (interleukin-1beta, 6, 8, tumour necrosis factor-alpha, and soluble receptor of interleukin-2) and C- 
reactive protein in the diagnosis of neonatal sepsis. Acta Paediatr 2003; 92(2): 221-7.

[41] Ventetuolo CE, Levy MM. Biomarkers: diagnosis and risk assessment in sepsis. Clin Chest Med 2008; 29(4): 591-603, vii.

[42] Routsi C, Giamarellos-Bourboulis EJ, Antonopoulou A, et al. Does soluble triggering receptor expressed on myeloid cells-1 play any role in the pathogenesis of septic shock? Clin Exp Immunol 2005; 142(1): 62-7.

[43] Gibot S, Cravoisy A, Kolopp-Sarda MN, et al. Time-course of sTREM (soluble triggering receptor expressed on myeloid cells)-1, procalcitonin, and C-reactive protein plasma concentrations during sepsis. Crit Care Med 2005; 33(4): 792-6.

[44] Dimopoulou I, Orfanos SE, Pelekanou A, et al. Serum of patients with septic shock stimulates the expression of Trem-1 on U937 monocytes. Inflamm Res 2009; 58(3): 127-32.

[45] Gibot S, Buonsanti C, Massin F, et al. Modulation of the triggering receptor expressed on the myeloid cell type 1 pathway in murine septic shock. Infect Immun 2006; 74(5): 2823-30.

[46] Bopp C, Hofer S, Bouchon A, Zimmermann JB, Martin E, Weigand MA. Soluble TREM-1 is not suitable for distinguishing between systemic inflammatory response syndrome and sepsis survivors and nonsurvivors in the early stage of acute inflammation. Eur J Anaesthesiol 2009; 26(6): 504-7.

[47] Sama AE, D'Amore J, Ward MF, Chen G, Wang H. Bench to bedside: HMGB1-a novel proinflammatory cytokine and potential therapeutic target for septic patients in the emergency department. Acad Emerg Med 2004; 11(8): 867-73.

[48] Dinarello CA, Gelfand JA, Wolff SM. Anticytokine strategies in the treatment of the systemic inflammatory response syndrome. JAMA 1993; 269(14): 1829-35.

[49] Wang H, Bloom O, Zhang M, et al. HMG-1 as a late mediator of endotoxin lethality in mice. Science 1999; 285(5425): 248-51.

[50] Wang H, Yang H, Czura CJ, Sama AE, Tracey KJ. HMGB1 as a late mediator of lethal systemic inflammation. Am J Respir Crit Care Med 2001; 164(10 Pt 1): 1768-73.

[51] Ulloa L, Ochani M, Yang H, et al. Ethyl pyruvate prevents lethality in mice with established lethal sepsis and systemic inflammation. Proc Natl Acad Sci U S A 2002; 99(19): 12351-6.
[52] Yang H, Ochani M, Li J, et al. Reversing established sepsis with antagonists of endogenous high-mobility group box 1 . Proc Natl Acad Sci U S A 2004; 101(1): 296-301.

[53] Abraham E, Arcaroli J, Carmody A, Wang H, Tracey KJ. HMG-1 as a mediator of acute lung inflammation. J Immunol 2000; 165(6): 2950-4.

[54] Hatada T, Wada H, Nobori T, et al. Plasma concentrations and importance of High Mobility Group Box protein in the prognosis of organ failure in patients with disseminated intravascular coagulation. Thromb Haemost 2005; 94(5): 975-9.

[55] Sakamoto Y, Mashiko K, Matsumoto H, et al. Effect of direct hemoperfusion with a polymyxin B immobilized fiber column on high mobility group box-1 (HMGB-1) in severe septic shock: report of a case. ASAIO J 2006; 52(6): e37-9.

[56] Sakamoto Y, Mashiko K, Obata T, et al. Clinical responses and improvement of some laboratory parameters following polymyxin B-immobilized fiber treatment in septic shock. ASAIO J 2007; 53(5): 646-50.

[57] Wong HR, Cvijanovich N, Wheeler DS, et al. Interleukin-8 as a stratification tool for interventional trials involving pediatric septic shock. Am J Respir Crit Care Med 2008; 178(3): 276-82.

[58] Isaacman DJ, Burke BL. Utility of the serum C-reactive protein for detection of occult bacterial infection in children. Arch Pediatr Adolesc Med 2002; 156(9): 905-9.

[59] Pulliam PN, Attia MW, Cronan KM. C-reactive protein in febrile children 1 to 36 months of age with clinically undetectable serious bacterial infection. Pediatrics 2001; 108(6): 1275-9.

[60] Lacour AG, Gervaix A, Zamora SA, et al. Procalcitonin, IL-6, IL8 , IL-1 receptor antagonist and C-reactive protein as identificators of serious bacterial infections in children with fever without localising signs. Eur J Pediatr 2001; 160(2): 95-100.

[61] Galetto-Lacour A, Zamora SA, Gervaix A. Bedside procalcitonin and C-reactive protein tests in children with fever without localizing signs of infection seen in a referral center. Pediatrics 2003; 112(5): 1054-60.

[62] Berger RM, Berger MY, van Steensel-Moll HA, Dzoljic-Danilovic G, Derksen-Lubsen G. A predictive model to estimate the risk of serious bacterial infections in febrile infants. Eur J Pediatr 1996; 155(6): 468-73.

Received: June 05, 2011

(c) Smith and Bigham; Licensee Bentham Open.

This is an open access article licensed under the terms of the Creative Commons Attribution Non-Commercial License (http: //creativecommons.org/licenses/by-nc/3.0/) which permits unrestricted, non-commercial use, distribution and reproduction in any medium, provided the work is properly cited. 